\title{
Impaired body perception in developmental prosopagnosia
}

\section{Article}

\section{Accepted Version}

Creative Commons: Attribution-Noncommercial-No Derivative Works 4.0

Biotti, F., Gray, K. L. H. and Cook, R. (2017) Impaired body perception in developmental prosopagnosia. Cortex, 93. pp. 41-49. ISSN 0010-9452 doi:

https://doi.org/10.1016/j.cortex.2017.05.006 Available at https://centaur.reading.ac.uk/70381/

It is advisable to refer to the publisher's version if you intend to cite from the work. See Guidance on citing.

To link to this article DOI: http://dx.doi.org/10.1016/j.cortex.2017.05.006

Publisher: Elsevier

All outputs in CentAUR are protected by Intellectual Property Rights law, including copyright law. Copyright and IPR is retained by the creators or other copyright holders. Terms and conditions for use of this material are defined in the End User Agreement.

\section{www.reading.ac.uk/centaur}

\section{CentAUR}

Central Archive at the University of Reading

Reading's research outputs online 
In press at: Cortex

Format: Research article

Running head: Body perception in developmental prosopagnosia

\title{
Impaired body perception in developmental prosopagnosia
}

\author{
Federica Biotti $^{1 *}$, Katie L. H. Gray ${ }^{2}$, Richard Cook ${ }^{1}$ \\ ${ }^{1}$ Department of Psychology, \\ City, University of London, London, U.K. \\ ${ }^{2}$ School of Psychology and Clinical Language Sciences, \\ University of Reading, Reading, U.K.
}

*Corresponding author: Federica.Biotti@city.ac.uk

Department of Psychology

City, University of London

Whiskin Street

London, UK

EC1R 0JD 


\section{Highlights}

- Developmental prosopagnosics and controls completed a match-to-sample procedure

- We compared observers' matching performance for faces, cars, and bodies

- At the group level, prosopagnosics were less accurate in all conditions

- Individual differences in body and car perception ability were unrelated 


\begin{abstract}
Developmental prosopagnosia (DP) is a lifelong neurodevelopmental disorder associated with difficulties recognising and discriminating faces. In some cases, the perceptual deficits seen in DP appear to be face-specific. However, DP is known to be a heterogeneous condition, and many cases undoubtedly exhibit impaired perception of other complex objects. There are several well-documented parallels between body and face perception; for example, faces and bodies are both thought to recruit holistic analysis and engage similar regions of visual cortex. In light of these similarities, individuals who exhibit face perception deficits, possibly due to impaired holistic processing or aberrant white matter connectivity, might also show cooccurring deficits of body perception. The present study therefore sought to investigate body perception in DP using a sensitive delayed match-to-sample task and a sizeable group of DPs. To determine whether body perception deficits, where observed, co-vary with wider object recognition deficits, observers' face and body matching ability was compared with performance in a car matching condition. Relative to age-matched controls, the DP sample exhibited impaired body matching accuracy at the group level, and several members of the sample were impaired at the single-case level. Consistent with previous reports of wider object recognition difficulties, a number of the DPs also showed evidence of impaired car recognition.
\end{abstract}

\title{
Key words:
}

Developmental prosopagnosia, face perception, body perception, object recognition 


\section{Introduction}

Developmental prosopagnosia $^{1}$ (DP) is a lifelong neurodevelopmental disorder associated with difficulties recognising familiar faces and deficits of unfamiliar face discrimination. The condition occurs in people with normal intelligence, typical low-level vision, and with no apparent brain lesions (Behrmann \& Avidan, 2005; Duchaine \& Nakayama, 2006b; Susilo \& Duchaine, 2013). As many as one in every 50 people are thought to experience lifelong face recognition difficulties severe enough to disrupt their daily lives (Kennerknecht et al., 2006; Kennerknecht, Ho, \& Wong, 2008). Individuals with DP identify others using non-face cues, including hairstyle, voice, and gait. Consequently, DPs often experience great difficulty when familiar people are met in unusual contexts or when they alter their appearance (Cook \& Biotti, 2016; Shah, Gaule, Sowden, Bird, \& Cook, 2015). In addition to problems recognising facial identity, some DPs also exhibit problems perceiving facial emotion (Biotti \& Cook, 2016; Duchaine, Yovel, Butterworth, \& Nakayama, 2006).

DP frequently runs in families, indicating that the condition has a genetic component (Duchaine, Germine, \& Nakayama, 2007; Johnen et al., 2014; Schmalzl, Palermo, \& Coltheart, 2008). However, the origins of DP remain poorly understood. From a cognitive perspective, reduced holistic processing - whereby information from disparate facial regions is integrated into a unified perceptual description - may underlie the face recognition difficulties seen in DP (Avidan, Tanzer, \& Behrmann, 2011; DeGutis, Cohan, Mercado, Wilmer, \& Nakayama, 2012; DeGutis, Cohan, \& Nakayama, 2014; Palermo et al., 2011). At the neurological level, studies have revealed reduced grey matter volume in occipitotemporal cortex of individuals with DP (Behrmann, Avidan, Gao, \& Black, 2007; Garrido et al., 2009), and have suggested atypical functional connectivity in high-level visual areas (Avidan \& Behrmann, 2009; Avidan et al., 2013; Lohse et al., 2016). In addition, recent studies have revealed striking white matter differences in the occipital and temporal lobes of DPs (Gomez et al., 2015; Song et al., 2015; Thomas et al., 2009). Reduced density and coherence of the inferior longitudinal fasciculus (ILF) may impair information exchange within the face processing network.

In some cases, the perceptual deficits seen in DP appear to be face-specific; many individuals achieve perfect or near-perfect performance on standardised object recognition batteries (e.g., Bentin, Deouell, \& Soroker, 1999; Nunn, Postma, \& Pearson, 2001). For example, Duchaine and colleagues (2006) described Edward, a 53-year old male, who exhibited a pure case of DP. Despite severe face recognition difficulties, Edward showed typical recognition of a range of 
objects including cars, tools, guns, horses, and sunglasses. Moreover, Edward was able to discriminate houses either on the basis on of elemental or configural differences, and showed typical learning and individuation of Greebles. However, DP is known to be a heterogeneous condition, and many cases undoubtedly exhibit impaired perception of other complex objects (Behrmann, Avidan, Marotta, \& Kimchi, 2005; Dalrymple, Elison, \& Duchaine, 2016; De Haan \& Campbell, 1991; Duchaine et al., 2007). For example, of seven siblings with DP tested by Duchaine and colleagues (2007), five were significantly impaired at car perception, and 3 showed significant gun perception deficits. The extent to which cases of DP are face-specific or extend to other classes of object, may depend on the nature and extent of an individual's aberrant white matter connectivity (see Gomez et al., 2015).

There has been much interest in potential similarities between the visual processing of faces and bodies in typical observers (de Gelder et al., 2009; Minnebusch \& Daum, 2009; Peelen \& Downing, 2007; Slaughter, Stone, \& Reed, 2004). Like faces, bodies are salient stimuli that capture attention when other classes of object go undetected (Downing, Bray, Rogers, \& Childs, 2004; Stein, Sterzer, \& Peelen, 2012). Faces and bodies both appear to preferentially engage regions of visual cortex. Strikingly, two areas thought to play a crucial role in body perception, the extrastriate (EBA; Downing, Jiang, Shuman, \& Kanwisher, 2001) and fusiform (FBA; Peelen \& Downing, 2005) body areas, are spatially adjacent to the occipital (OFA; Pitcher, Walsh, \& Duchaine, 2011) and fusiform (FFA; Kanwisher \& Yovel, 2006) face areas, respectively, suggestive of parallel networks (Peelen \& Downing, 2007). Similar event-related brain potentials (ERPs) are elicited by both faces (N170; Bentin, Allison, Puce, Perez, \& McCarthy, 1996; Eimer, 2011) and bodies (N190; Stekelenburg \& de Gelder, 2004; Thierry et al., 2006). Both the N170 and N190 components are delayed and increased when stimuli are presented upside-down, however their origin appears to be distinct and dissociable (Sadeh et al., 2011).

There has also been great interest in whether or not bodies recruit holistic processing similar to that engaged by faces. Composite effects, whereby the presence of an aligned task-irrelevant region alters observers' perception of a target region, provide direct evidence of holistic face processing (Murphy, Gray, \& Cook, 2016; Rossion, 2013). Interestingly, similar composite effects have recently been reported with expressive body postures (Willems, Vrancken, Germeys, \& Verfaillie, 2014), but not for body shapes in neutral poses (Bauser, Suchan, \& Daum, 2011). Sizeable inversion effects, often cited as an indirect measure of holistic 
processing, are seen for both faces and bodies (Cook \& Duchaine, 2011; Robbins \& Coltheart, 2012a). Inversion effects are particularly strong when participants are required to match sequentially presented body postures (Reed, Stone, Bozova, \& Tanaka, 2003; Reed, Stone, Grubb, \& McGoldrick, 2006). It is unclear, however, whether these effects reveal holistic body processing; for example, the magnitude of the posture inversion effect is disproportionately affected by the presence and position of the head (Yovel, Pelc, \& Lubetzky, 2010).

Where individuals exhibit deficits of face perception, possibly due to impaired holistic processing or aberrant white matter connectivity, one might therefore expect co-occurring deficits of body perception. Consistent with this intuition, Righart and de Gelder (2007) found that the N170 marker of body processing exhibits atypical modulation following orientation inversion in three observers with DP. Nevertheless, many DPs report using body shape and bodily motion cues to recognise others (Biotti \& Cook, 2016), and several empirical results suggest that body perception may be broadly typical in this population. For example, a recent study found no differences in torso matching accuracy when a sample of 11 DPs were compared with matched controls $^{2}$ (Rivolta, Lawson, \& Palermo, 2016). Similarly, a sample of 16 DPs exhibited typical discrimination of hands - stimuli known to elicit strong responses in EBA (see Peelen \& Downing, 2007) - in a match-to-sample procedure (Shah, Gaule, Gaigg, Bird, \& Cook, 2015). Typical body matching has also been described in individual cases of DP (Duchaine et al., 2006). DPs and matched controls show broadly similar responses to body stimuli in core areas of the body processing network, including EBA and FBA (Van den Stock, van de Riet, Righart, \& de Gelder, 2008), and multi-voxel pattern analysis (MVPA) suggests that distributed neural representations of body stimuli in inferotemporal cortex are largely typical (Rivolta et al., 2014).

The present study sought to investigate body perception in DP through the use of a sensitive identity matching task of headless torsos, using a sizeable group of DPs $(N=20)$. Individual differences in body matching ability were compared with performance in comparable car and face matching conditions. In light of the equivocal literature on body perception in DP, we anticipated a range of abilities in our sample. However, we were interested in the possibility that co-occurring deficits of body perception, where observed, may co-vary with wider object recognition deficits described previously (Behrmann et al., 2005; Dalrymple et al., 2016; De Haan \& Campbell, 1991; Duchaine et al., 2007). In neurotypical individuals, the perception of faces, bodies, and objects is thought to rely on functionally and spatially distinct networks 
(Pitcher, Charles, Devlin, Walsh, \& Duchaine, 2009). However, the diffuse white matter differences seen in some cases of DP (Gomez et al., 2015; Song et al., 2015; Thomas et al., 2009) may predispose individuals to a range of perceptual deficits.

\section{Method}

\subsection{Participants}

Participants were 43 right-handed adults, 20 with (6 males; $M_{\text {age }}=38.04$ years, $S D_{\text {age }}=13.05$ years) and 23 without DP (9 males; $M_{\text {age }}=40.30$ years, $S D_{\text {age }}=14.38$ years). The groups did not differ significantly in age $[t(41)=.54, p=.593]$ or proportion of males $\left[X^{2}(1)=.09, p=\right.$ .760]. Ethical approval was granted by the local ethics committee. The study was conducted in line with the ethical guidelines provided by the $6^{\text {th }}$ (2008) Declaration of Helsinki. All participants provided informed consent.

\subsection{Diagnostic testing}

DP participants were recruited through www.troublewithfaces.org. All members of the DP sample described lifelong face recognition difficulties. None of the DPs had a history of brain injury or psychiatric disorder (e.g., schizophrenia, autism spectrum disorder). Diagnostic evidence for the presence of DP was collected using the Cambridge Face Memory Test (CFMT; Duchaine \& Nakayama, 2006a), the Cambridge Face Perception Test (CFPT; Duchaine et al., 2007) and the Twenty-Item Prosopagnosia Index (PI20; Shah, Gaule, Sowden et al., 2015). The prosopagnosics' scores on the diagnostic procedures were compared with a group of 56 age-matched controls $\left(M_{\text {age }}=40.25\right.$ years, $S D_{\text {age }}=13.71$ years, 24 males $)$. All DPs scored at least two standard deviations below the mean of the comparison sample on the PI20 (Table 1). All but one of the DPs scored at least two standard deviations below the comparison average on the CFMT; the remaining DP scored -1.86 standard deviations below the comparison average. Thirteen of the DPs also scored two standard deviations below the comparison average

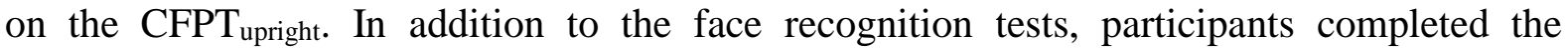
Cambridge Car Memory Test (CCMT; Dennett et al., 2011), to assess their wider object recognition ability, and were screened for colour blindness using Ishihara's Tests for ColourBlindness (Ishihara, 1993).

Table-1

\subsection{Stimuli}


Each category (faces, bodies, cars) comprised fifty exemplars (Figure 1). Individual categories were further organised into five subsets of ten exemplars based on approximate similarity. Each exemplar was depicted twice: once in frontal view, once in 3/4 view. When viewed at $57 \mathrm{~cm}$, the face and body stimuli subtended $11^{\circ}$ of visual angle vertically; the cars subtended $8^{\circ}$ vertically. Face stimuli (male Caucasian faces) were created using FaceGen Modeller Version 3.3 (Singular Inversions Inc.). Body stimuli (Caucasian male torsos) were created with Poser 7.0 (e frontier America, Inc.). Car stimuli (black saloon / sedan cars and SUVs) were generated through www.3dtuning.com. The use of torsos prevented observers employing simple limbmatching strategies and allowed us to present body stimuli a scale that accentuated 3D shape variation. We note that torsos, unlike other body parts, elicit strong responses both the EBA and FBA (Taylor, Wiggett, \& Downing, 2007).

\subsection{Procedure}

Testing took place at City, University of London. Trials started with a fixation point (750 ms), before a single target stimulus was presented centrally (400 ms). Targets were always shown in frontal view. A retention interval $(3000 \mathrm{~ms})$ followed target offset. A mask image constructed by recombining regions cropped from other target images from the same category - was presented throughout the retention interval. An array of four test items followed the retention interval. The array comprised the target and three lures from the same within-category subset, all shown in 3/4 view ${ }^{3}$. Test arrays were visible until a keypress response was registered. Participants were asked to locate the target item with speed and accuracy. All stimuli appeared as a target once, yielding 150 experimental trials, which were preceded by six practice trials. Trial type (Face, Body, Car) was interleaved within each mini-block. No feedback was provided during the procedure. The task lasted approximately 30 minutes and included three short breaks. The matching task was programmed in MATLAB using the Psychophysics Toolbox (Brainard, 1997; Pelli, 1997).

Figure-1

\section{Results}

\subsection{Group analyses}

Matching accuracy (\% correct; Figure $2 a$ ) was analysed using ANOVA with Category (bodies, cars, faces) as a within-subjects factor and Group (DP, TD) as a between-subjects factor. The analysis revealed significant main effects of Category $\left[F(2,82)=5.29, p=.007, \eta_{\mathrm{p}}{ }^{2}=.11\right]$, and 
Group $\left[F(2,41)=24.03, p<.001, \eta_{\mathrm{p}}^{2}=.37\right]$, as well as a significant Group $\times$ Category interaction $\left[F(2,82)=5.46, p=.006, \eta_{\mathrm{p}}{ }^{2}=.19\right]$. As expected, simple contrasts indicated that the DP group $(M=.45, S D=.13)$ was less accurate at face matching than the TD group $(M=$ $.66, S D=.15)[t(41)=4.97, p<.001]$. Crucially, however, the TD group also outperformed the DP group when matching bodies (TD: $M=.54, S D=.09$; DP: $M=.46, S D=.09)[t(41)=$ $2.69, p=.01]$ and cars (TD: $M=.61, S D=.14$; DP: $M=.53, S D=.10)[t(41)=2.16, p=$ .036]. The relative performance of individual DPs in the three conditions is shown in Figure 3.

Figure-2 / Figure-3

The analysis of response times (RTs; Figure $2 b$ ) revealed a main effect of Category $[F(2,82)=$ $\left.9.66, p<.001, \eta_{\mathrm{p}}^{2}=.19\right]$. Generally participants were slower when matching cars $(M=4118$, $S D=1662)$, than faces $(M=3629, S D=1169)[t(42)=2.35, p=.024]$ or bodies $(M=3428$, $S D=1069)[t(42)=4.34, p<.001]$. RTs were also significantly slower on face trials, than on body trials $[t(42)=2.16, p=.036]$. The analysis revealed no main effect of Group $[F(2,41)=$ $\left..22, p=.638, \eta_{\mathrm{p}}^{2}=.005\right]$, nor a Group $\times$ Category interaction $\left[F(2,82)=1.5, p=.229, \eta_{\mathrm{p}}^{2}=\right.$ $.035]$.

\subsection{Correlational analyses}

In addition to the group-level analyses, we also examined the individual differences seen on our matching task using correlational analyses (Table 2). For the purposes of these analyses, we collapsed across the control $(N=23)$ and DP $(N=20)$ groups to yield a combined sample of 43. It is clear, however, that correlations described with larger sample sizes are associated with greater power and increased stability (e.g., Schönbrodt \& Perugini, 2013).

We began by confirming that performance in our face and car conditions correlated with our diagnostic measures of face and car perception. Strong correlations were observed between participants' matching accuracy in the face condition and their scores on the CFMT $(r=.77, p$ $<.001)$, PI20 ( $r=-.66, p<.001)$, and CFPT $(r=-.71, p<.001)$. Performance in the cars condition also correlated with scores on the CCMT $(r=.57, p<.001)$.

Next we sought to compare matching accuracy for bodies and cars with measures of face perception. Body matching accuracy correlated with scores on the CFMT $(r=.46, p=.002)$, PI20 ( $r=-.31, p=.04)$, and CFPT $(r=-.41, p=.006)$. Moderate correlations were found 
between car matching accuracy and both CFMT $(r=.39, p=.009)$ and CFPT scores $(r=-.37$, $p=.015)$. Matching accuracy for bodies $(r=.51, p<.001)$ and cars $(r=.31, p=.046)$ correlated with performance in the face condition (Figure 2c).

Finally, we sought to compare our measures of body and car perception. Interestingly, we failed to find significant correlations between body and car matching accuracy, either in the combined sample $(r=.23, p=.14)$, in the TD sample $(r=.04, p=.86)$, or in the DP sample $(r=.25, p=$ .28). We also failed to find any relationship between CCMT scores and performance in our body condition in the combined sample $(r=.16, p=.30)$, in the TD sample $(r=.07, p=.75)$, or in the DP sample $(r=.06, p=.79)$.

To compare the strength of correlations observed in the combined sample we used Steiger's (1980) modification of Dunn and Clark's $z$ (1969), implemented using the 'cocor' package (Diedenhofen \& Musch, 2015) in R. There was some indication that the strength of the facebody correlation exceeded that of the body-car correlation $[z=1.7, p=.045$ (one-tailed)]. However, the strength of the face-body $[z=1.2, p=.12$ (one-tailed) $]$ and body-car correlations $[z=.52, p=.3$ (one-tailed) $]$ did not differ significantly from the face-car correlation.

Table-2

\section{Discussion}

The present study sought to determine whether body perception is impaired in DP. Relative to age-matched TD controls, the DP sample exhibited impaired body matching accuracy at the group level, and several members of the sample were impaired at the single case level. These results provide the clearest behavioural evidence of impaired body perception in DP reported to date. Previous findings suggest that, in some cases of DP, ERP markers of body processing fail to show typical modulation by stimulus orientation (Righart \& de Gelder, 2007). At the behavioural level, however, typical body matching accuracy has been described (Duchaine et al., 2006; Rivolta et al., 2016; Shah, Gaule, Gaigg et al., 2015). Our use of a larger DP sample and a sensitive task likely helped reveal body perception deficits. Consistent with previous reports (Behrmann et al., 2005; Dalrymple et al., 2016; De Haan \& Campbell, 1991; Duchaine et al., 2007), a number of the DPs in the present study also showed evidence of wider object recognition difficulties. At the group level, the DPs were less accurate in the car matching condition than TD observers, and several DPs showed signs of impairment on the CCMT. 
Evidence of body perception deficits in DP accords with well-documented parallels between body and face perception (de Gelder et al., 2009; Minnebusch \& Daum, 2009; Peelen \& Downing, 2007; Slaughter et al., 2004). For example, the EBA-FBA and OFA-FFA networks for body and face processing, respectively, recruit spatially adjacent regions of occiptotemporal cortex (Peelen \& Downing, 2007). Indeed, the FFA and FBA partially overlap in some observers (Peelen \& Downing, 2005). Given the diffuse white matter differences described in occipitotemporal regions of some DPs (Gomez et al., 2015; Thomas et al., 2009), entirely typical body perception would be surprising. Similarly, the accurate perception of face and body shape may depend on holistic processing (Murphy et al., 2016; Robbins \& Coltheart, 2012a, 2012b). Should cases of DP result from atypical holistic processing (Avidan et al., 2011; DeGutis et al., 2012; DeGutis et al., 2014; Palermo et al., 2011), one might therefore expect problems perceiving both faces and bodies.

While the incidence of body agnosia may be higher in DP than in the typical population, body perception deficits do not appear to be a universal feature of DP. At the group level, the deficits do not appear to be as strong as for faces, and only 4 of the DPs exhibited significant body perception deficits at the single-case level. Again, this is not surprising given previous evidence that the perceptual processing of bodies and faces appears to dissociate. For example, neuropsychological patients have been described who exhibit severely impaired body perception, but spared face perception (Moscovitch, Winocur, \& Behrmann, 1997). Conversely, other patients exhibit severe face recognition, but typical body perception (Susilo, Yovel, Barton, \& Duchaine, 2013). The application of transcranial magnetic stimulation to EBA and OFA also appears to selectively impair the perception of bodies and faces, respectively (Pitcher et al., 2009).

In light of co-occurring deficits of body and car perception, it is tempting to conclude that DPs have a domain general perceptual deficit. Interestingly, however, we observed little or no relationship between observers' car perception ability and their body perception. While findings from small samples must be treated with caution (e.g., Schönbrodt \& Perugini, 2013), we speculate that forms of developmental agnosia affecting the perception of faces, bodies, and objects may be best thought of as independent neurodevelopmental conditions. A key feature of neurodevelopmental conditions is that they co-occur; for example the incidence of several conditions is elevated in ASD relative to the typical population (Baron-Cohen et al., 2013; Bird 
\& Cook, 2013; Dziuk et al., 2007; Jones et al., 2009; Matson \& Shoemaker, 2009; van Steijn et al., 2014). Though often overlooked by vision scientists, it is widely recognised in psychiatry that genetic or environmental factors that predispose an individual to one developmental condition, often increase their risk of developing others (Bishop \& Rutter, 2008; Gilger \& Kaplan, 2001; Kaplan, Dewey, Crawford, \& Wilson, 2001; Rutter, 1997; Rutter et al., 2011).Observers predisposed to developing DP may therefore be at risk from developing body agnosia, and wider object recognition difficulties. 


\section{Footnotes}

${ }^{1}$ We use the term developmental prosopagnosia instead of congenital prosopagnosia to indicate the possibility that in some cases the disorder may appear during development and not necessarily from birth.

${ }^{2}$ While prosopagnosics and controls did not differ in body matching accuracy, the prosopagnosics responded slower.

${ }^{3}$ The requirement to identify exemplars across different viewpoints prevents the use of simple image matching strategies; instead, observers must form a view-invariant 3-dimensional representation of the target (e.g., Longmore, Liu, \& Young, 2008). 


\section{References}

Avidan, G., \& Behrmann, M. (2009). Functional MRI reveals compromised neural integrity of the face processing network in congenital prosopagnosia. Current Biology, 19(13), 1146-1150.

Avidan, G., Tanzer, M., \& Behrmann, M. (2011). Impaired holistic processing in congenital prosopagnosia. Neuropsychologia, 49(9), 2541-2552.

Avidan, G., Tanzer, M., Hadj-Bouziane, F., Liu, N., Ungerleider, L. G., \& Behrmann, M. (2013). Selective dissociation between core and extended regions of the face processing network in congenital prosopagnosia. Cerebral Cortex, 24(6), 1565-1578.

Baron-Cohen, S., Johnson, D., Asher, J., Wheelwright, S., Fisher, S. E., Gregersen, P. K., et al. (2013). Is synaesthesia more common in autism? Molecular Autism, 4(40), 1-6.

Bauser, D. A. S., Suchan, B., \& Daum, I. (2011). Differences between perception of human faces and body shapes: Evidence from the composite illusion. Vision research, 51(1), 195-202.

Behrmann, M., \& Avidan, G. (2005). Congenital prosopagnosia: face-blind from birth. Trends in Cognitive Sciences, 9(4), 180-187.

Behrmann, M., Avidan, G., Gao, F., \& Black, S. (2007). Structural imaging reveals anatomical alterations in inferotemporal cortex in congential prosopagnosia. Cerebral Cortex, 17(10), 2354-2363.

Behrmann, M., Avidan, G., Marotta, J. J., \& Kimchi, R. (2005). Detailed exploration of facerelated processing in congenital prosopagnosia: 1. Behavioral findings. Journal of Cognitive Neuroscience, 17(7), 1130-1149.

Bentin, S., Allison, T., Puce, A., Perez, E., \& McCarthy, G. (1996). Electrophysiological studies of face perception in humans. Journal of Cognitive Neuroscience, 8, 551-565. 
Bentin, S., Deouell, L. Y., \& Soroker, N. (1999). Selective visual streaming in face recognition: Evidence from developmental prosopagnosia. Neuroreport, 10(4), 823827.

Biotti, F., \& Cook, R. (2016). Impaired perception of facial emotion in developmental prosopagnosia. Cortex, 81, 126-136.

Bird, G., \& Cook, R. (2013). Mixed emotions: the contribution of alexithymia to the emotional symptoms of autism. Translational Psychiatry, 3, e285.

Bishop, D. V. M., \& Rutter, M. (2008). Neurodevelopmental disorders: conceptual issues. In M. Rutter, D. V. M. Bishop, D. Pine, S. Scott, J. Stevenson, E. A. Taylor \& A. Thapar (Eds.), Rutter's Child and Adolescent Psychiatry (pp. 32-41). Oxford, UK: Blackwell.

Brainard, D. H. (1997). The psychophysics toolbox. Spatial Vision, 10(4), 433-436.

Cook, R., \& Biotti, F. (2016). Developmental prosopagnosia. Current Biology, 26(8), R312R313.

Cook, R., \& Duchaine, B. (2011). A look at how we look at others: Orientation inversion and photographic negation disrupt the perception of human bodies. Visual Cognition, 19(4), 445-468.

Dalrymple, K. A., Elison, J. T., \& Duchaine, B. (2016). Face-specific and domain-general visual processing deficits in children with developmental prosopagnosia. The Quarterly Journal of Experimental Psychology, 1-17.

de Gelder, B., Van den Stock, J., Meeren, H. K., Sinke, C. B., Kret, M. E., \& Tamietto, M. (2009). Standing up for the body. Recent progress in uncovering the networks involved in the perception of bodies and bodily expressions. Neuroscience \& Biobehavioral Reviews, 34(4), 513-527.

De Haan, E. H., \& Campbell, R. (1991). A fifteen year follow-up of a case of developmental prosopagnosia. Cortex, 27(4), 489-509. 
DeGutis, J., Cohan, S., Mercado, R. J., Wilmer, J., \& Nakayama, K. (2012). Holistic processing of the mouth but not the eyes in developmental prosopagnosia. Cognitive Neuropsychology, 29(5-6), 419-446.

DeGutis, J., Cohan, S., \& Nakayama, K. (2014). Holistic face training enhances face processing in developmental prosopagnosia. Brain, 137(Pt 6), 1781-1798.

Dennett, H. W., McKone, E., Tavashmi, R., Hall, A., Pidcock, M., Edwards, M., et al. (2011). The Cambridge Car Memory Test: a task matched in format to the Cambridge Face Memory Test, with norms, reliability, sex differences, dissociations from face memory, and expertise effects. Behavior Research Methods, 44(2), 587-605.

Diedenhofen, B., \& Musch, J. (2015). cocor: a comprehensive solution for the statistical comparison of correlations. PLoS One, 10(3), e0121945.

Downing, P. E., Bray, D., Rogers, J., \& Childs, C. (2004). Bodies capture attention when nothing is expected. Cognition, 93(1), B27-B38.

Downing, P. E., Jiang, Y., Shuman, M., \& Kanwisher, N. (2001). A cortical area selective for visual processing of the human body. Science, 293(5539), 2470-2473.

Duchaine, B., Germine, L., \& Nakayama, K. (2007). Family resemblance: ten family members with prosopagnosia and within-class object agnosia. Cognitive Neuropsychology, 24(4), 419-430.

Duchaine, B., \& Nakayama, K. (2006a). The Cambridge Face Memory Test: results for neurologically intact individuals and an investigation of its validity using inverted face stimuli and prosopagnosic participants. Neuropsychologia, 44(4), 576-585.

Duchaine, B., \& Nakayama, K. (2006b). Developmental prosopagnosia: a window to contentspecific face processing. Current Opinion in Neurobiology, 16, 166-173.

Duchaine, B., Yovel, G., Butterworth, E., \& Nakayama, K. (2006). Prosopagnosia as an impairment to face-specific mechanisms: Elimination of the alternative hypotheses in a developmental case. Cognitive Neuropsychology, 23(5), 714-747. 
Dunn, O. J., \& Clark, V. A. (1969). Correlation coefficients measured on the same individuals. Journal of the American Statistical Association, 64, 366-377.

Dziuk, M. A., Larson, J. C., Apostu, A., Mahone, E. M., Denckla, M. B., \& Mostofsky, S. H. (2007). Dyspraxia in autism: association with motor, social, and communicative deficits. Developmental Medicine and Child Neurology, 49(10), 734-739.

Eimer, M. (2011). The face-sensitive N170 component of the event-related brain potential. In A. J. Calder, G. Rhodes, M. Johnson \& J. Haxby (Eds.), The Oxford Handbook of Face Perception (Vol. 28, pp. 329-344). Oxford: Oxford University Press.

Garrido, L., Furl, N., Draganski, B., Weiskopf, N., Stevens, J., Tan, G. C. Y., et al. (2009). Voxel-based morphometry reveals reduced grey matter volume in the temporal cortex of developmental prosopagnosics. Brain, 132, 3443-3455.

Gilger, J. W., \& Kaplan, B. J. (2001). Atypical brain development: a conceptual framework for understanding developmental learning disabilities. Developmental Neuropsychology, 20(2), 465-481.

Gomez, J., Pestilli, F., Witthoft, N., Golarai, G., Liberman, A., Poltoratski, S., et al. (2015). Functionally defined white matter reveals segregated pathways in human ventral temporal cortex associated with category-specific processing. Neuron, 85(1), 216-227.

Ishihara, S. (1993). Ishihara's Tests for Colour-Blindness. Tokyo, Japan: Kanehara.

Johnen, A., Schmukle, S. C., Hüttenbrink, J., Kischka, C., Kennerknecht, I., \& Dobel, C. (2014). A family at risk: Congenital prosopagnosia, poor face recognition and visuoperceptual deficits within one family. Neuropsychologia, 58, 52-63.

Jones, C. R., Happe, F., Golden, H., Marsden, A. J., Tregay, J., Simonoff, E., et al. (2009). Reading and arithmetic in adolescents with autism spectrum disorders: peaks and dips in attainment. Neuropsychology, 23(6), 718-728. 
Kanwisher, N., \& Yovel, G. (2006). The fusiform face area: a cortical region specialized for the perception of faces. Philosophical Transactions of the Royal Society of London B: Biological Sciences, 361(1476), 2109-2128.

Kaplan, B. J., Dewey, D. M., Crawford, S. G., \& Wilson, B. N. (2001). The term comorbidity is of questionable value in reference to developmental disorders: data and theory. Journal of Learning Disabilities, 34(6), 555-565.

Kennerknecht, I., Grüter, T., Welling, B., Wentzek, S., Horst, J., Edwards, S., et al. (2006). First report of prevalence of non-syndromic hereditary prosopagnosia (HPA). American Journal of Medical Genetics, 140A(15), 1617-1622.

Kennerknecht, I., Ho, N. Y., \& Wong, V. C. N. (2008). Prevalence of heriditary prosopagonsia (HPA) in Hong Kong Chinese population. American Journal of Medical Genetics, 146A(22), 2863-2870.

Lohse, M., Garrido, L., Driver, J., Dolan, R. J., Duchaine, B. C., \& Furl, N. (2016). Effective connectivity from early visual cortex to posterior occipitotemporal face areas supports face selectivity and predicts developmental prosopagnosia. Journal of Neuroscience, 36(13), 3821-3828.

Longmore, C. A., Liu, C. H., \& Young, A. W. (2008). Learning faces from photographs. Journal of Experimental Psychology: Human Perception and Performance, 34, 77100.

Matson, J. L., \& Shoemaker, M. (2009). Intellectual disability and its relationship to autism spectrum disorders. Research in Developmental Disabilities, 30(6), 1107-1114.

Minnebusch, D. A., \& Daum, I. (2009). Neuropsychological mechanisms of visual face and body perception. Neuroscience \& Biobehavioral Reviews, 33(7), 1133-1144.

Moscovitch, M., Winocur, G., \& Behrmann, M. (1997). What is special about face recognition? Nineteen experiments on a person with visual object agnosia and dyslexia but normal face recognition. Journal of Cognitive Neuroscience, 9(5), 555604. 
Murphy, J., Gray, K. L. H., \& Cook, R. (2016). The composite face illusion. Psychonomic Bulletin \& Review.

Nunn, J. A., Postma, P., \& Pearson, R. (2001). Developmental prosopagnosia: should it be taken at face value? Neurocase, 7(1), 15-27.

Palermo, R., Willis, M. L., Rivolta, D., McKone, E., Wilson, C. E., \& Calder, A. J. (2011). Impaired holistic coding of facial expression and facial identity in congenital prosopagnosia. Neuropsychologia, 49(5), 1226-1235.

Peelen, M. V., \& Downing, P. E. (2005). Selectivity for the human body in the fusiform gyrus. Journal of Neurophysiology, 93(1), 603-608.

Peelen, M. V., \& Downing, P. E. (2007). The neural basis of visual body perception. Nature Reviews Neuroscience, 8(8), 636-648.

Pelli, D. G. (1997). The VideoToolbox software for visual psychophysics: transforming numbers into movies. Spatial Vision, 10(4), 437-442.

Pitcher, D., Charles, L., Devlin, J. T., Walsh, V., \& Duchaine, B. (2009). Triple dissociation of faces, bodies, and objects in extrastriate cortex. Current Biology, 19(4), 319-324.

Pitcher, D., Walsh, V., \& Duchaine, B. (2011). The role of the occipital face area in the cortical face perception network. Experimental Brain Research, 209(4), 481-493.

Reed, C. L., Stone, V. E., Bozova, S., \& Tanaka, J. (2003). The body-inversion effect. Psychological Science, 14(4), 302-308.

Reed, C. L., Stone, V. E., Grubb, J. D., \& McGoldrick, J. E. (2006). Turning configural processing upside down: Part and whole body postures. Journal of Experimental Psychology-Human Perception and Performance, 32(1), 73-86.

Righart, R., \& de Gelder, B. (2007). Impaired face and body perception in developmental prosopagnosia. Proceedings of the National Academy of Sciences, 104(43), 1723417238. 
Rivolta, D., Lawson, R. P., \& Palermo, R. (2016). More than just a problem with faces: altered body perception in a group of congenital prosopagnosics. The Quarterly Journal of Experimental Psychology, 1-11.

Rivolta, D., Woolgar, A., Palermo, R., Butko, M., Schmalzl, L., \& Williams, M. A. (2014). Multi-voxel pattern analysis (MVPA) reveals abnormal fMRI activity in both the 'core' and 'extended' face network in congenital prosopagnosia. Frontiers in Human Neuroscience, 8 .

Robbins, R. A., \& Coltheart, M. (2012a). The effects of inversion and familiarity on face versus body cues to person recognition. Journal of Experimental Psychology: Human Perception and Performance, 38(5), 1098.

Robbins, R. A., \& Coltheart, M. (2012b). Left-right holistic integration of human bodies. The Quarterly Journal of Experimental Psychology, 65(10), 1962-1974.

Rossion, B. (2013). The composite face illusion: A whole window into our understanding of holistic face perception. Visual Cognition, 21(2), 139-253.

Rutter, M. (1997). Comorbidity: concepts, claims and choices. Criminal Behaviour and Mental Health, 7(4), 265-285.

Rutter, M., Bishop, D., Pine, D., Scott, S., Stevenson, J. S., Taylor, E. A., et al. (2011). Rutter's Child and Adolescent Psychiatry. New York: John Wiley \& Sons.

Sadeh, B., Pitcher, D., Brandman, T., Eisen, A., Thaler, A., \& Yovel, G. (2011). Stimulation of category-selective brain areas modulates ERP to their preferred categories. Current Biology, 21(22), 1894-1899.

Schmalzl, L., Palermo, R., \& Coltheart, M. (2008). Cognitive heterogeneity in genetically based prosopagnosia: a family study. Journal of Neuropsychology, 2(Pt 1), 99-117.

Schönbrodt, F. D., \& Perugini, M. (2013). At what sample size do correlations stabilize? Journal of Research in Personality, 47(5), 609-612. 
Shah, P., Gaule, A., Gaigg, S. B., Bird, G., \& Cook, R. (2015). Probing short-term face memory in developmental prosopagnosia. Cortex, 64, 115-122.

Shah, P., Gaule, A., Sowden, S., Bird, G., \& Cook, R. (2015). The 20-item prosopagnosia index (PI20): a self-report instrument for identifying developmental prosopagnosia. Royal Society Open Science, 2(6), 140343.

Slaughter, V., Stone, V. E., \& Reed, C. L. (2004). Perception of faces and bodies similar or different? Current Directions in Psychological Science, 13(6), 219-223.

Song, S., Garrido, L., Nagy, Z., Mohammadi, S., Steel, A., Driver, J., et al. (2015). Local but not long-range microstructural differences of the ventral temporal cortex in developmental prosopagnosia. Neuropsychologia, 78, 195-206.

Steiger, J. H. (1980). Tests for comparing elements of a correlation matrix. Psychological Bulletin, 87, 245-251.

Stein, T., Sterzer, P., \& Peelen, M. V. (2012). Privileged detection of conspecifics: Evidence from inversion effects during continuous flash suppression. Cognition, 125(1), 64-79.

Stekelenburg, J. J., \& de Gelder, B. (2004). The neural correlates of perceiving human bodies: an ERP study on the body-inversion effect. Neuroreport, 15(5), 777-780.

Susilo, T., \& Duchaine, B. (2013). Advances in developmental prosopagnosia research. Current Opinion in Neurobiology, 23, 423-429.

Susilo, T., Yovel, G., Barton, J. J. S., \& Duchaine, B. (2013). Face perception is categorysepcific: Evidence from normal body perception in acquired prosopagnosia. Cognition, 129(1), 88-94.

Taylor, J. C., Wiggett, A. J., \& Downing, P. E. (2007). Functional MRI analysis of body and body part representations in the extrastriate and fusiform body areas. Journal of Neurophysiology, 98(3), 1626-1633. 
Thierry, G., Pegna, A. J., Dodds, C., Roberts, M., Basan, S., \& Downing, P. (2006). An event-related potential component sensitive to images of the human body. Neuroimage, 32(2), 871-879.

Thomas, C., Avidan, G., Humphreys, K., Jung, K. J., Gao, F., \& Behrmann, M. (2009). Reduced structural connectivity in ventral visual cortex in congential prosopagnosia. Nature Neuroscience, 12, 29-31.

Van den Stock, J., van de Riet, W. A. C., Righart, R., \& de Gelder, B. (2008). Neural correlates of perceiving emotional faces and bodies in developmental prosopagnosia: an event-related fMRI-study. PloS one, 3(9), e3195.

van Steijn, D. J., Richards, J. S., Oerlemans, A. M., de Ruiter, S. W., van Aken, M. A., Franke, B., et al. (2014). The co-occurrence of autism spectrum disorder and attention-deficit/hyperactivity disorder symptoms in parents of children with ASD or ASD with ADHD. Journal of Child Psychology and Psychiatry, 53(9), 954-963.

Willems, S., Vrancken, L., Germeys, F., \& Verfaillie, K. (2014). Holistic processing of human body postures: evidence from the composite effect. Frontiers in Psychology, 5, 618.

Yovel, G., Pelc, T., \& Lubetzky, I. (2010). It's all in your head: why is the body inversion effect abolished for headless bodies? Journal of Experimental Psychology: Human Perception and Performance, 36(3), 759-767. 


\section{Figures}

Figure 1

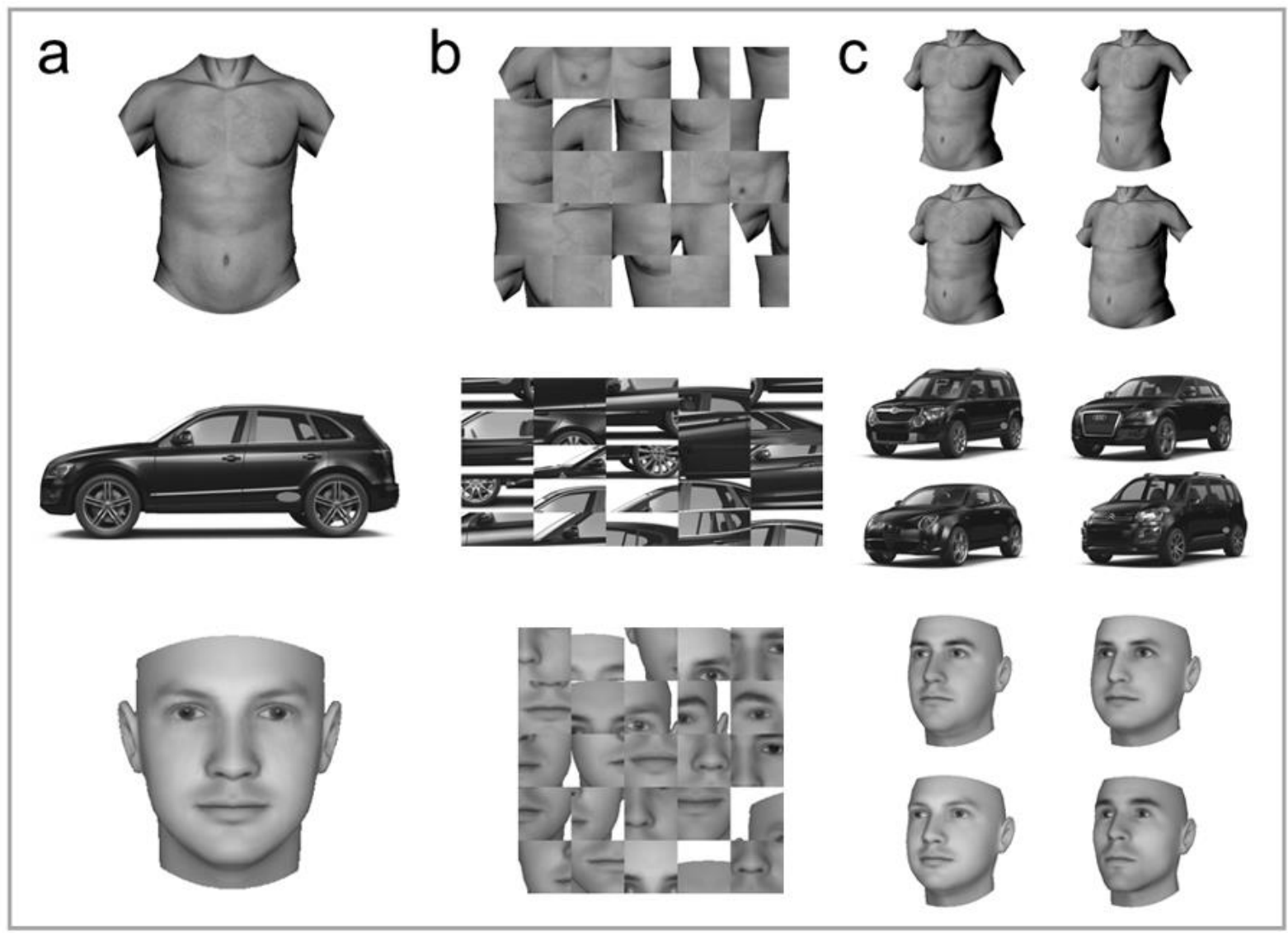

Figure 1. (a) Target stimuli were presented in frontal view for $400 \mathrm{~ms}$. (b) During the retention interval (3000 ms) a mask was presented, constructed by recombining regions cropped from other target images from the same category. (c) Test arrays presented the target and three lures in $3 / 4$ views. 
Figure 2
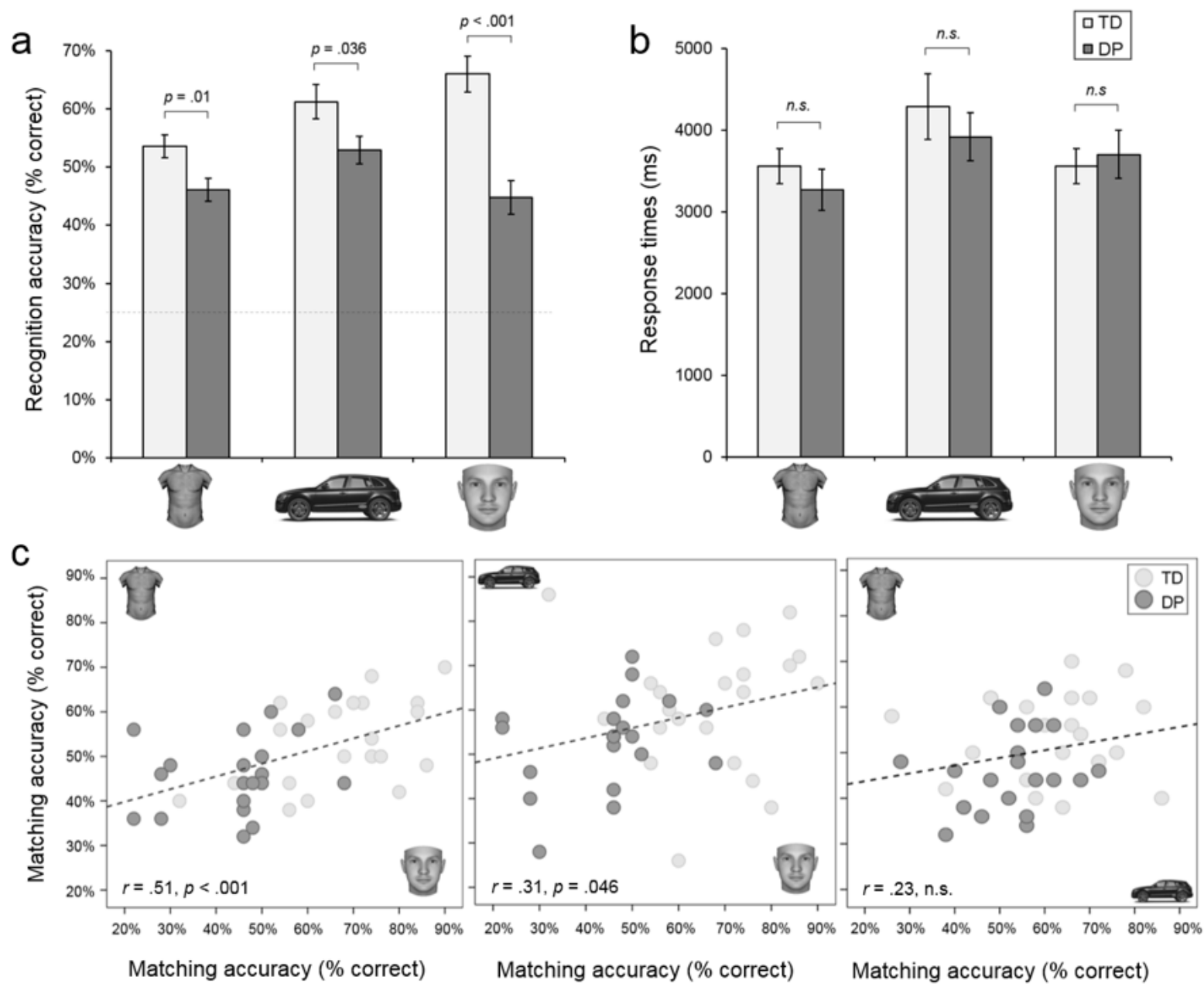

Figure 2. (a) Mean matching accuracy and (b) mean response times for the typically developing (TD) controls and the developmental prosopagnosics (DPs) in the three conditions. Error bars denote \pm one SEM. (c) Scatter plots comparing participants' matching accuracy in the three conditions. 


\section{Figure 3}
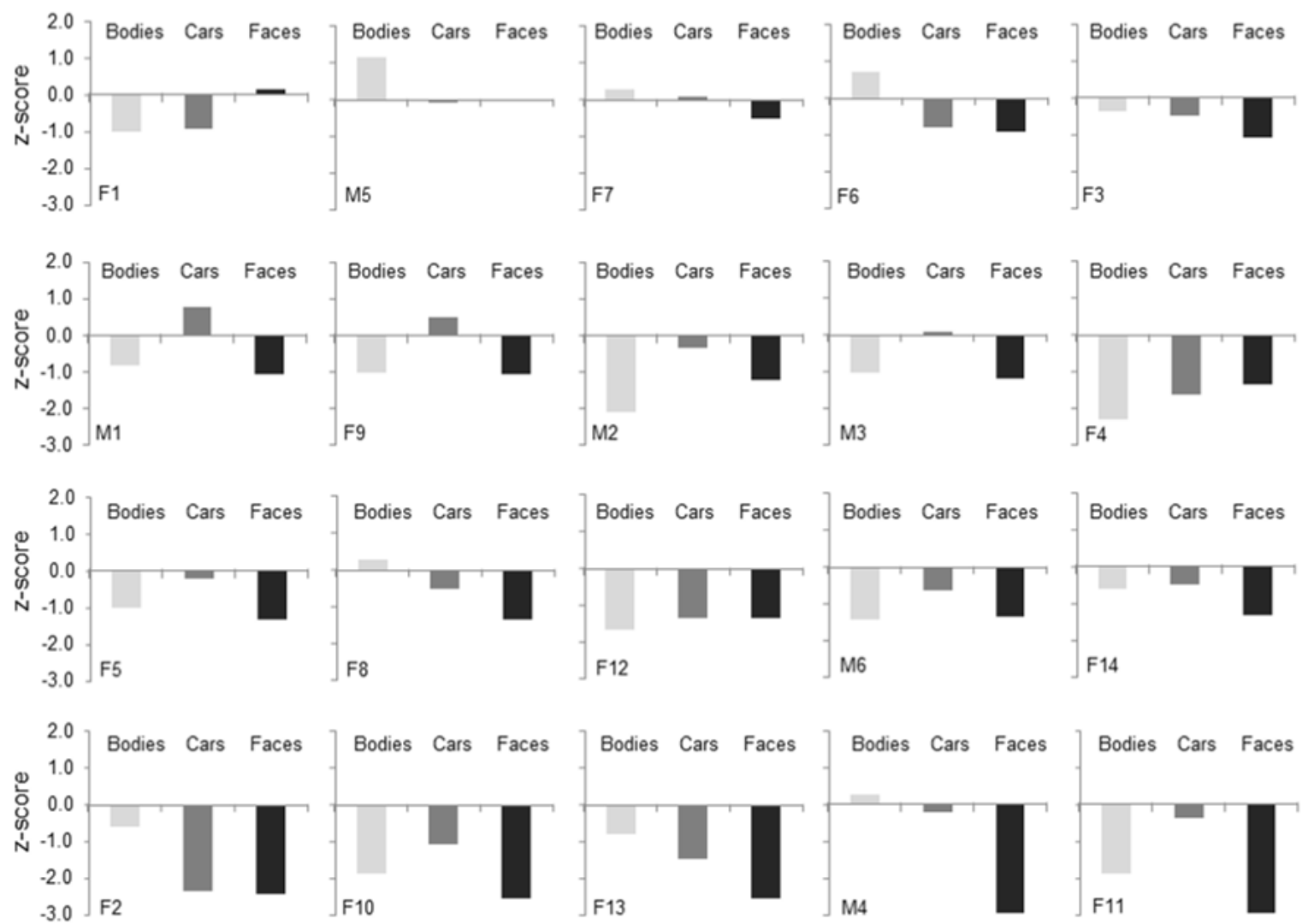

Figure 3. Single-case data for the members of the DP group. For ease of comparison, cases are ordered by performance in the face matching condition. A z-score of zero denotes performance comparable with the mean of the control group. 


\section{Table}

Table 1. Scores of each developmental prosopagnosic on the Twenty-Item Prosopagnosia Index (PI20), the Cambridge Face Perception Test (CFPT), the Cambridge Face Memory Test (CFMT), and the Cambridge Car Memory Test (CCMT). Higher scores on the CFPT and PI20 indicate poorer face recognition. The mean and standard deviation of the comparison sample $(\mathrm{N}=56)$ are provided below.

\begin{tabular}{ccccccc}
\hline Participant & Age & PI20 & $\begin{array}{c}\text { CFPT } \\
\text { upright }\end{array}$ & $\begin{array}{c}\text { CFPT } \\
\text { inverted }\end{array}$ & CFMT \% & CCMT\% \\
\hline F1 & 21 & 59 & 30 & 64 & 63.89 & 51.39 \\
F2 & 22 & 80 & 66 & 98 & 40.28 & 56.94 \\
F3 & 48 & 85 & 60 & 70 & 63.89 & 59.72 \\
F4 & 66 & 79 & 40 & 70 & 61.11 & 66.67 \\
F5 & 49 & 82 & 62 & 68 & 62.50 & 68.06 \\
F6 & 48 & 78 & 26 & 64 & 58.33 & 61.11 \\
F7 & 23 & 82 & 38 & 48 & 65.28 & 80.56 \\
F8 & 56 & 91 & 30 & 60 & 54.17 & 55.56 \\
F9 & 23 & 84 & 52 & 70 & 66.67 & 100.0 \\
F10 & 47 & 75 & 46 & 78 & 50.00 & 72.22 \\
F11 & 46 & 92 & 72 & 78 & 50.00 & 47.22 \\
F12 & 29 & 83 & 66 & 84 & 51.39 & 62.50 \\
F13 & 54 & 85 & 74 & 94 & 45.83 & 63.89 \\
F14 & 25 & 70 & 74 & 68 & 44.44 & 54.17 \\
M1 & 30 & 85 & 48 & 84 & 59.72 & 65.28 \\
M2 & 58 & 82 & 52 & 56 & 68.06 & 59.72 \\
M3 & 56 & 82 & 54 & 78 & 66.67 & 79.17 \\
M4 & 36 & 77 & 44 & 42 & 40.28 & 68.06 \\
M5 & 26 & 82 & 54 & 48 & 65.28 & 66.67 \\
M6 & 43 & 83 & 48 & 54 & 40.28 & 59.72 \\
\hline TD mean & 40.25 & 37.75 & 29.57 & 60.00 & 84.82 & 64.98 \\
TD SD & 13.71 & 9.16 & 9.24 & 14.47 & 9.02 & 14.42 \\
\hline
\end{tabular}

